\title{
Alcohol Reduces Prefrontal Cortical Excitability in Humans: A Combined TMS and EEG Study
}

\author{
Seppo Kähkönen*,I,2,4, Juha Wilenius', Vadim V Nikulin ${ }^{1,4}$, Marko Ollikainen ${ }^{3}$ and Risto J IImoniemi ${ }^{1,4}$ \\ 'BioMag Laboratory, Engineering Centre, Helsinki University Central Hospital, Helsinki, Finland; ${ }^{2}$ Cognitive Brain Research Unit, University of \\ Helsinki, Helsinki, Finland; ${ }^{3}$ Nexstim Ltd, Helsinki, Finland; ${ }^{4}$ Helsinki Brain Research Center, Helsinki, Finland
}

\begin{abstract}
The effects of alcohol $(0.8 \mathrm{~g} / \mathrm{kg})$ on the prefrontal cortex were studied in nine healthy subjects using the technique of transcranial magnetic stimulation (TMS) combined with electroencephalography (EEG). A total of 120 magnetic pulses were delivered with a figureof-eight coil to the left prefrontal cortex at the rate of $0.4-0.7 \mathrm{~Hz}$. The EEG was recorded simultaneously with 60 scalp electrodes (4I electrodes were used for analysis); the TMS-evoked activation was estimated by the area under the global mean field amplitude (GMFA) time curve. TMS caused changes in EEG activity lasting up to 270 ms poststimulus. Alcohol decreased GMFA at 30-270 ms poststimulus $(7 / 3 \pm 303$ vs $478 \pm 142 \mu \mathrm{Vms} ; p=0.007)$. Alcohol-induced differences were most pronounced at anterior electrodes. These results suggest that alcohol reduces the excitability in the prefrontal cortex.

Neuropsychopharmacology (2003) 28, 747-754. doi:I 0.1038/sj.npp. 1300099
\end{abstract}

Keywords: alcohol; electroencephalography; prefrontal cortex; transcranial magnetic stimulation

\section{INTRODUCTION}

The mechanisms by which alcohol produces its moodaltering and behavioral effects are poorly understood. One approach for studying these mechanisms is to monitor neural activity after alcohol ingestion. A number of studies in humans have examined the effects of intoxication on different frequencies of brain electrical activity. Studies examining the effects of moderate doses of alcohol on spontaneous EEG have generally reported an increase of $\alpha$ rhythm amplitude and a decrease of the dominant $\alpha$ frequency (Lukas et al, 1986). With larger doses, an increase in the lower frequencies is observed (Lehtinen et al, 1985). Low doses may produce alterations in $\theta(4-7 \mathrm{~Hz})$ and in slow $\alpha$ activity (8-9 Hz) (Ehlers et al, 1989). However, no information about the brain structures underlying the EEG changes is available.

Other studies have examined the effects of alcohol on regional cerebral blood flow ( $\mathrm{rCBF}$ ) and glucose utilization (CMRglu) yielding conflicting results. Investigators have found decreased rCBF in cerebellum and increased $\mathrm{rCBF}$ in the parietal and prefrontal cortex (Volkow et al, 1990), increased $\mathrm{rCBF}$ in the frontal cortex only (Matthew and

\footnotetext{
*Correspondence: Dr S Kähkönen, BioMag Laboratory, Helsinki University Central Hospital, PO Box 340, FIN-00029 HUS, Finland, Tel: + I 3589 47/75542, Fax: + I 3589 47|7578I, E-mail: seppo.kahkonen@helsinki.fi

Received 26 April 2002; revised II October 2002; accepted 18 October 2002

Online publication: 23 October 2002 at http: //www.acnp.org/citations/ Npp I023024/4
}

Wilson, 1986), increased rCBF in the right prefrontal cortex (Tiihonen et al, 1994), and increased rCBF in all gray matter areas except the left anterior cortical areas (Newlin et al, 1982). Decreased CMRglu was found in frontal cortices (De Wit et al, 1990). The interpretation of $\mathrm{rCBF}$ data is complicated by the fact that alcohol has both vasodilatory and vasoconstrictive effects, which can change blood flow directly.

Transcranial magnetic stimulation (TMS) provides an experimental method for studying localized changes in the electrical properties of the human brain. In TMS, a timevarying magnetic field is generated by a current pulse through a stimulator coil placed above the head. This induces a flow of current in the brain, resulting in neural activation (Barker, 1991). Alcohol has been found to change motor cortex excitability studied by TMS (Ziemann et al, 1995).

Recently, TMS has been combined with electroencephalography (EEG) (Ilmoniemi et al, 1997; Kähkönen et al, 2001a, b; Komssi et al, 2002). With this approach, we have recently shown that acute alcohol ingestion is associated with alteration in excitability and functional connections of the motor cortex (Kähkönen et al, 2001a). Further, this study showed that the prefrontal cortex is affected by alcohol. TMS combined with EEG allows one to record responses to the stimulation of the prefrontal cortex (Kähkönen et al, 2001b). These responses are stimulusintensity dependent, that is, higher intensities produce greater brain activation (Kähkönen et al, 2002). In the present study, we investigated whether alcohol intoxication changes TMS-evoked EEG activity when the prefrontal cortex is stimulated directly. 


\section{METHODS}

\section{Subjects}

Nine healthy right-handed nonsmoking male volunteers $(25 \pm 3.7$ years) with no personal history of drug/ethanol abuse participated in the study. The subjects reported having no systemic, neurological, or psychiatric disorders; they used no medication. They were instructed to abstain from food for at least $3 \mathrm{~h}$ and from ethanol for at least $48 \mathrm{~h}$ prior to participation in the experiment. The study was approved by the local ethical committee. All subjects gave their written informed consent.

\section{Experimental Design and Ethanol Challenge}

Only males were included in this study to avoid sex-related differences in the alcohol challenge. Compared to men, women show a higher level of blood alcohol concentration (BAC) after the same dose of alcohol (Marshall et al, 1983). Subjects received the conditions in the same order: the baseline TMS-EEG study was followed by ethanol ingestion. They had $30 \mathrm{~min}$ to drink the ethanol $(0.8 \mathrm{~g} / \mathrm{kg})$ dissolved in $10 \%$ lemon-flavored solution. After a further 30-min waiting period, the repeated TMS-EEG experiment was performed. The BAC was tested using the SD-2 breath analyzer (Lion Laboratories, Barry, UK) before the alcohol ingestion and after ingestion of alcohol and waiting period.

\section{Magnetic Stimulation}

The subjects were seated in a comfortable reclining chair. Studies were performed while they had their eyes open; they used earplugs to avoid possible adverse effects of the auditory click produced by the TMS coil. The stimulation was performed by a figure-of-eight coil, which consisted of two coplanar circular loops $40 \mathrm{~mm}$ in diameter. The coil was placed above the left hemisphere and was oriented so that the induced current was in the posterior-anterior direction during the rising phase of the biphasic $320-\mu$ s pulse. After finding the optimal site for activating the right abductor digiti minimi (ADM), the stimulation intensity was adjusted to the motor threshold (MT). Motor evoked potentials were recorded with surface EMG with one electrode on the belly of the muscle and one on the proximal base of the phalange. The MT was determined as the intensity required to evoke the peak potential of at least $50 \mu \mathrm{V}$ in four out of eight trials. The left prefrontal cortex was defined as a point located $5 \mathrm{~cm}$ anterior and $2 \mathrm{~cm}$ lateral from the optimal $\mathrm{ADM}$ site. Magnetic pulses were delivered at a random interstimulus interval (ISI) of $1.5-2.5 \mathrm{~s}$. Previous studies have shown that TMS evokes complex EEG responses, which can contain an auditory and possibly also a somatosensory component (Nikouline et al, 1999; Tiitinen et al, 1999). TMS pulses are accompanied by a click of up to $130 \mathrm{~dB}$ (Starck et al, 1996). Since part of the auditory response is due to bone-conducted sound (Nikouline et al, 1999), we used a piece of plastic between the coil and the scalp to maintain bone conduction in the control condition, while significantly reducing induced electric field by $\sim 70 \%$. The experimental protocol consisted of two conditions before and after ethanol ingestion: (1) left prefrontal cortex
TMS ( $n=9$ ), with the coil pressed against the scalp; and (2) control prefrontal cortex condition (in six randomly selected subjects) with the coil $2 \mathrm{~cm}$ from the scalp, but with a piece of plastic connecting the head and the coil. A separate EMG control recording in one randomly selected subject was made in order to explore the possible muscle activity induced by the left prefrontal stimulation. In two conditions, two bipolar platinum needle electrodes were inserted to the main muscle mass of the left or right temporal muscle $3 \mathrm{~cm}$ apart. A separate electro-oculography (EOG) recording with two electrodes attached to the outer canthi of left and right eyes in one randomly selected subject was made to explore the possible artifacts related to eye movements. In each condition, at least 120 pulses were delivered.

\section{EEG}

The EEG was recorded from 60 scalp electrodes referred to the forehead. To avoid artifacts in the EEG caused by the TMS pulses, an EEG amplifier designed for TMS was used (Virtanen et al, 1999). Small Ag/AgCl C-shaped electrodes eliminated possible heating effects. Saturation of the EEG amplifiers during the TMS pulse was avoided by using a sample-and-hold circuit that pinned the amplifier output to a constant level during the brief pulse. The amplifiers were released from the constant output $5 \mathrm{~ms}$ after the end of the magnetic pulse. The signals were lowpass filtered at $250 \mathrm{~Hz}$ and sampled at the rate of $1450 \mathrm{~Hz}$. After the rejection of epochs contaminated with eye movements and muscle activity, at least 100 responses were averaged.

\section{Analysis}

After excluding all channels that appeared noisy at least in one subject, a set of 41 channels was used for the analysis. As prefrontal TMS activates ipsilateral and contralateral hemispheres (Kähkönen et al, 2001a,b), the global mean field amplitude (GMFA) was used as an indicator of the strength of an evoked field (Lehmann and Skrandies, 1980). The GMFA was calculated by the formula

$$
\frac{\sqrt{\sum_{i=1}^{N}\left(v_{i}-\bar{v}\right)^{2}}}{N},
$$

where $v_{i}$ is the potential at electrode $i, \bar{v}$ is the average potential of electrodes, and $N$ is their number. The TMSevoked EEG activation was estimated by the area under the GMFA time curve, which was calculated by the trapezoidal rule from 30 to $270 \mathrm{~ms}$. The time intervals for analysis were chosen on the basis of TMS responses being quickly varying (from 30 to $130 \mathrm{~ms}$ ) and slowly varying (from 130 to $270 \mathrm{~ms}$ ). Data were analyzed with two-factor (alcohol; before alcohol/after alcohol $\times$ poststimulus interval; early/late period) repeated measures analyses of variance (ANOVAs), separately for real TMS and real minus control TMS. Pair-wise comparison was made by the two-tailed paired $t$-test with a Bonferroni correction. The results are expressed as mean \pm standard deviation $(\mathrm{M} \pm \mathrm{SD})$. 


\section{RESULTS}

The baseline BAC was $0.0 \mathrm{ml} / \mathrm{l}$ in all subjects. At $30 \mathrm{~min}$ after the consumption of ethanol, the BAC was $0.76 \pm 0.14 \mathrm{ml} / \mathrm{l}$.

Left prefrontal TMS caused changes in GMFA activity lasting up to $270 \mathrm{~ms}$ poststimulus before alcohol ingestion. Figure 1 shows that the differences between before and after alcohol ingestion were largest in frontal and central electrodes.

Figure 2 shows alcohol-induced differences in GMFAs. ANOVA revealed a significant main effect on alcohol
$(\mathrm{F}(1,8)=12.9 ; p=0.007)$. No significant interaction between alcohol $\times$ poststimulus interval was observed. Paired $t$-test showed that the reduction of GMFA by alcohol was significant at $30-130 \mathrm{~ms}$ and at $130-270 \mathrm{~ms}$ (Table 1). After the subtraction of the control from the real TMS, ANOVA showed a significant main effect on alcohol $(\mathrm{F}(1,5)=8.9 ; p=0.03)$. No significant interaction between alcohol $\times$ poststimulus interval was found. In this subtraction the reduction of GMFA by alcohol was significant at $30-130 \mathrm{~ms}$ but not at $130-270 \mathrm{~ms}$ (Table 1 ). Figure 3 demonstrates that alcohol-induced differences

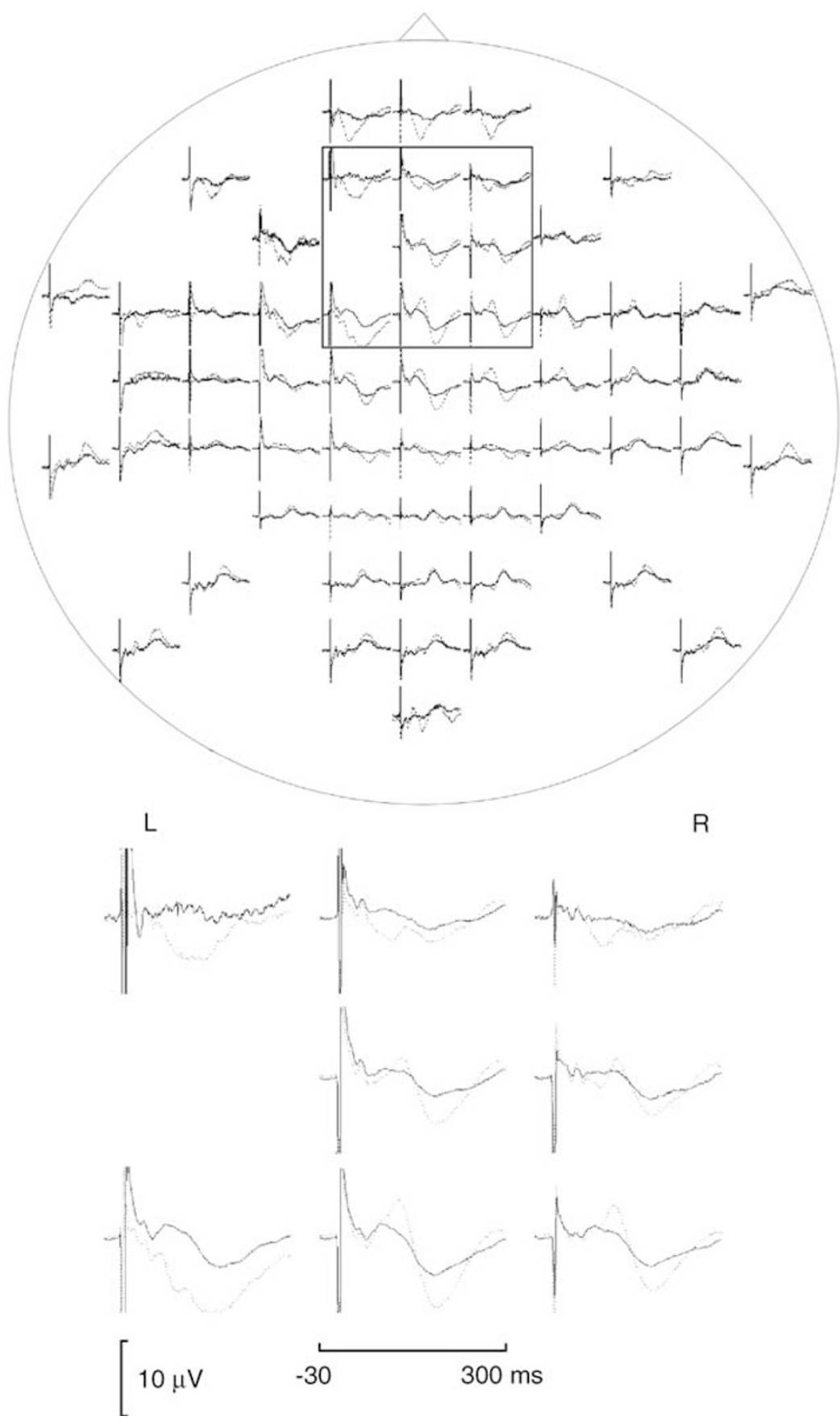

Figure I Grand average with common averaged referencing prefrontal TMS-evoked EEG responses before (dotted lines) and after alcohol (solid) challenge. Signals from frontal and central electrodes are enlarged. Artifacted electrodes were removed. Negativity is upward. 
Table I GMFA Before and After Alcohol Ingestion (M \pm SD)

\begin{tabular}{lcclcc}
\hline & \multicolumn{2}{c}{ Before alcohol $(\boldsymbol{\mu V} \mathbf{~ m s})$} & & \multicolumn{2}{c}{ After alcohol $(\boldsymbol{\mu V} \mathbf{m s})$} \\
\cline { 2 - 3 } Interval $(\mathbf{m s})$ & Real TMS & Real TMS-control & & Real TMS & Real TMS-control \\
\hline $30-130$ & $251 \pm 83$ & $210 \pm 80$ & & $160 \pm 49 * *$ & $156 \pm 44 *$ \\
$130-270$ & $462 \pm 230$ & $277 \pm 114$ & & $318 \pm 104 *$ & $230 \pm 87$ \\
\hline
\end{tabular}

*** $p<0.01$; $*<<0.05$, paired $t$-test with a Bonferroni correction. Before and after alcohol ingestion tested.

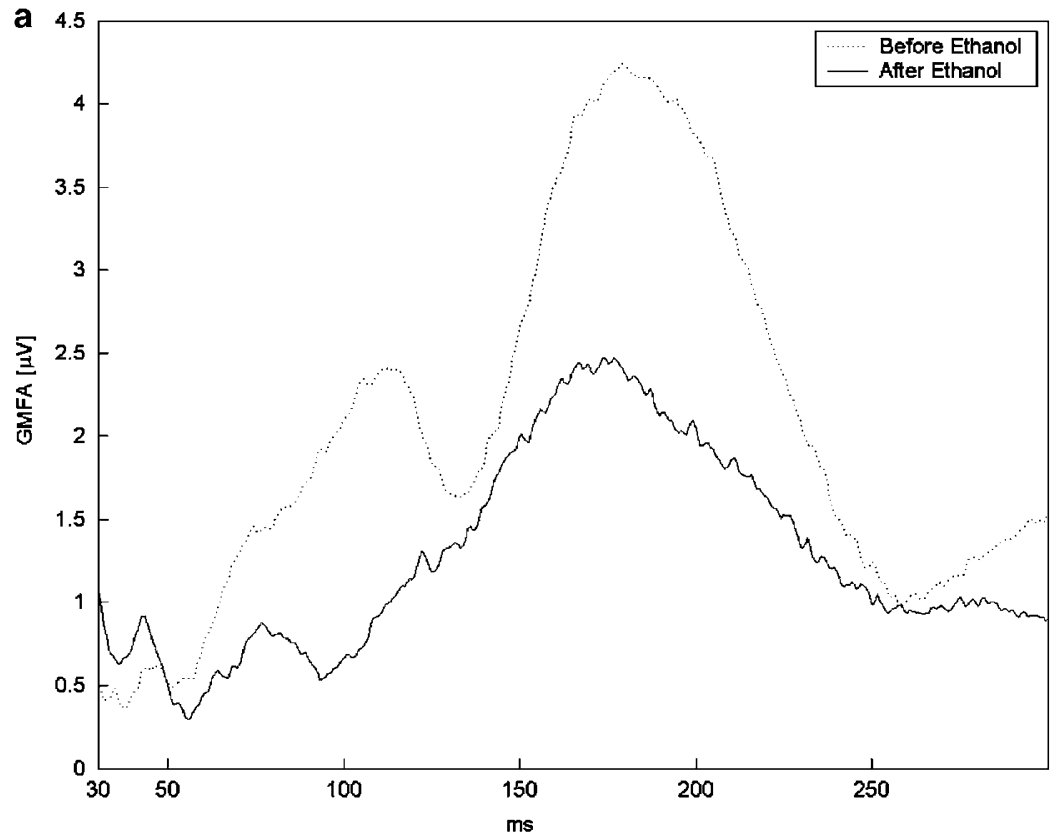

b

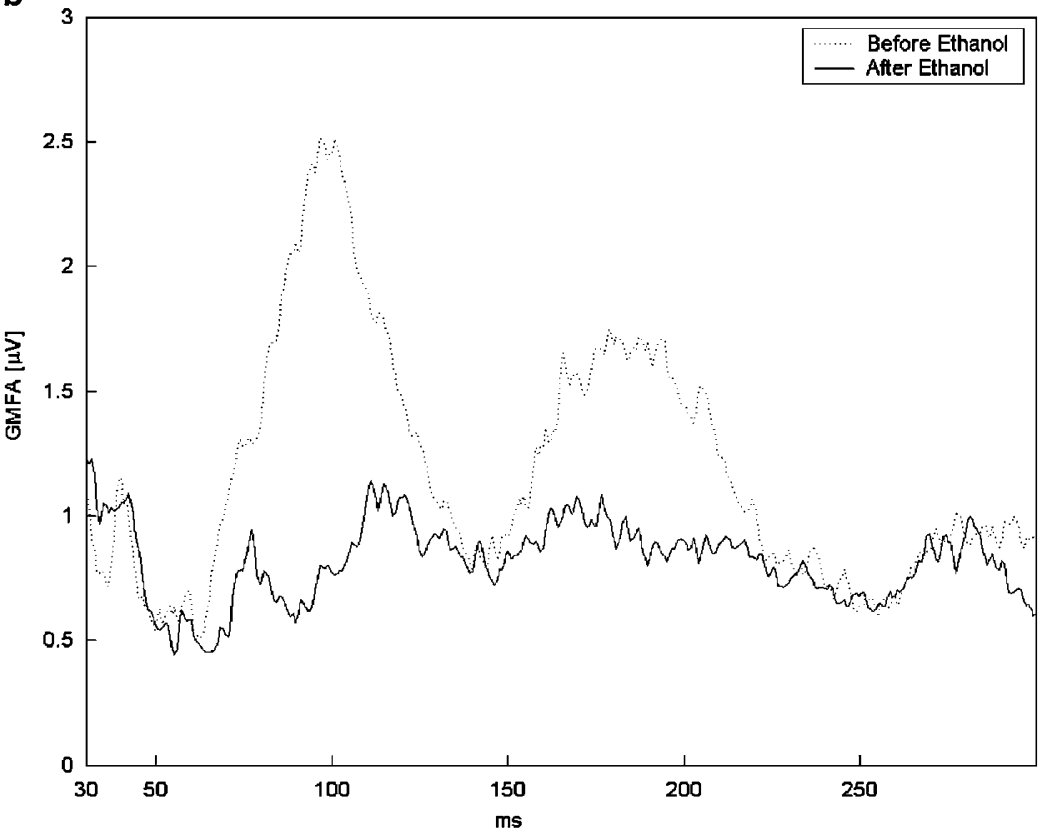

Figure 2 GMFA in the prefrontal real-TMS condition (a) and in the condition after subtracting the control from real TMS (b).

assessed by the paired $t$-test were most pronounced at anterior electrodes. EMG activity was observed up to $30 \mathrm{~ms}$ after stimulation (Figure $4 \mathrm{a}$ ). No significant EOG activity was measured after TMS (Figure $4 \mathrm{~b}$ ).

\section{DISCUSSION}

We investigated with prefrontal magnetic stimulation combined with EEG whether alcohol challenge changes 
a

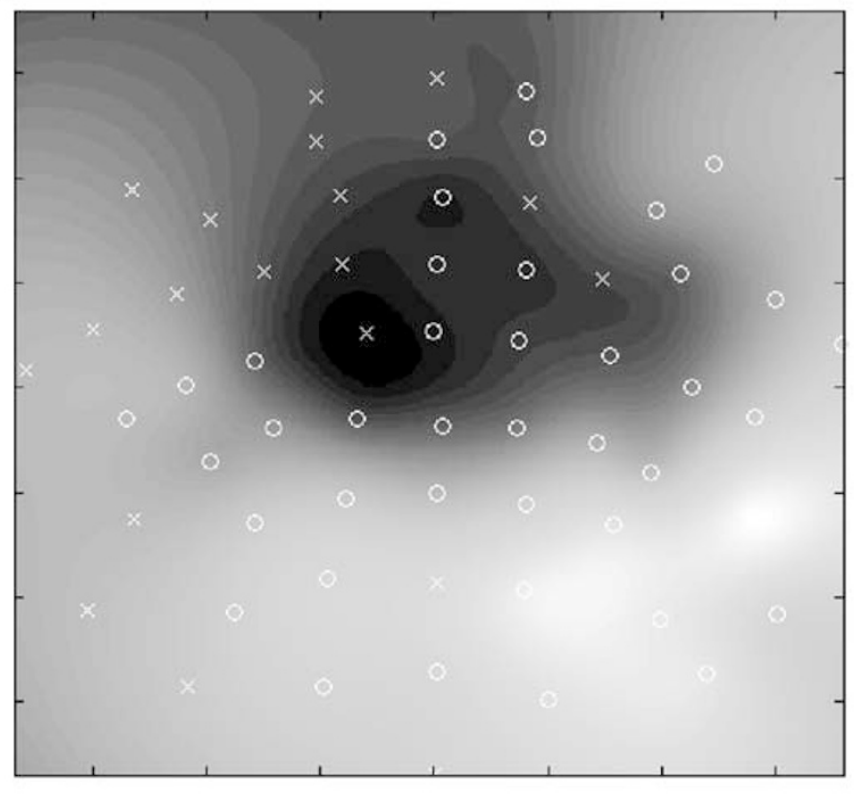

b

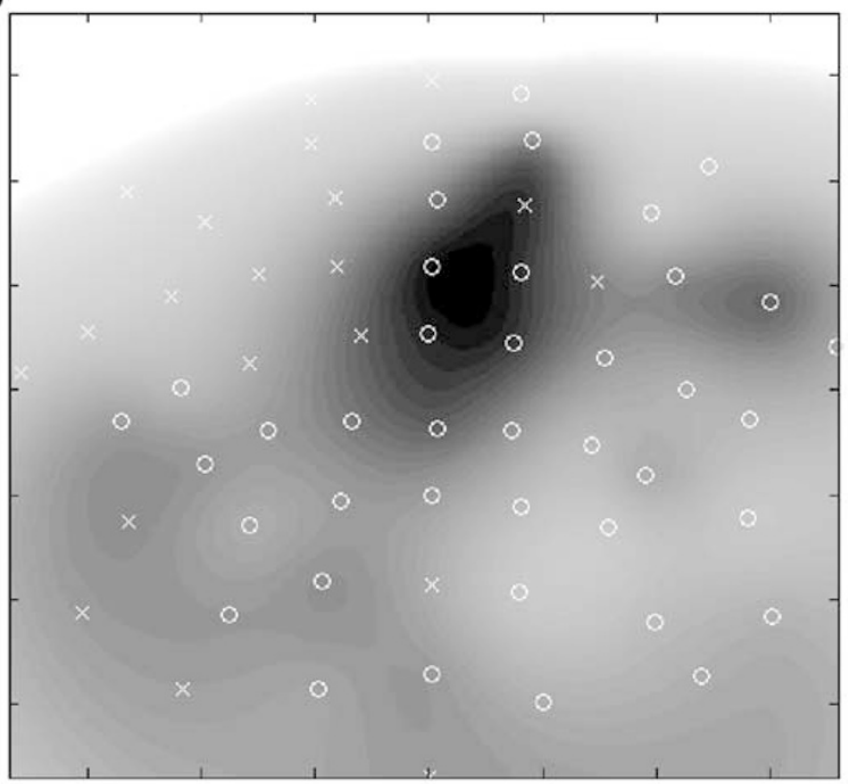

p-value
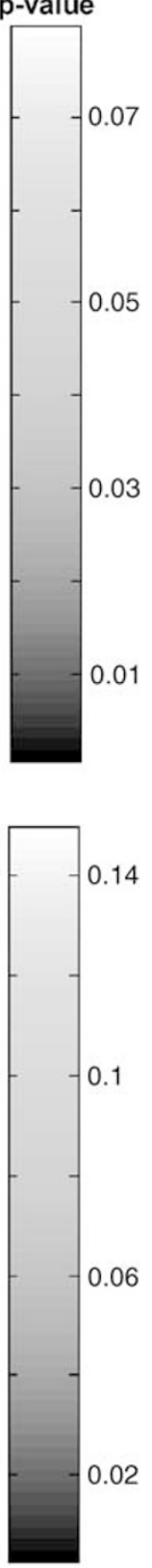

Figure 3 Paired t-test maps for the difference of time-integrated EEG responses from 30 to $270 \mathrm{~ms}$ (before and after alcohol ingestion) in the prefrontal real-TMS condition (a) and in the condition after subtracting the control from real TMS (b). Circles indicate electrodes used in analysis. Crosses indicate artifacted electrodes. The nose is upwards. Note the low p-values in anterior electrodes.

cortical reactivity. A novel finding was that acute alcohol ingestion decreases the GMFA after prefrontal cortex TMS, suggesting reduced cortical excitability. The reduction of GMFA was evident in the data also after the subtraction of the control from real TMS. This indicates that the results were not due to TMS-induced auditory activation. The strongest decrease was observed at anterior EEG electrodes. Other controls with EOG and EMG after TMS showed that the EEG changes did not result from eye movements or muscle twitches during the experiments.

Alcohol has been found to reduce motor cortex excitability by Ziemann et al (1995). In their study, TMS was combined with EMG, which gives only indirect evidence about the excitability of the motor cortex, because these responses might be modulated by spinal mechanisms (Morita et al, 1999; Nielsen et al, 1999a, b). In contract to this, we used the combination of TMS and EEG, which provides direct information about cortical excitability after stimulation of different sites (Ilmoniemi et al, 1997; Kähkönen et al, 2001a, b, 2002; Komssi et al, 2002).

Surface electrical stimulation of the motor cortex causes inhibitory postsynaptic potentials (IPSPs) through interneurons (Rosenthal et al, 1967). The IPSPs are probably $\gamma$ amino butyric acid (GABA)-mediated; ethanol has been shown to potentiate this inhibition (for a review, see Korpi, 1994). GABA mechanisms may constitute one of the factors 

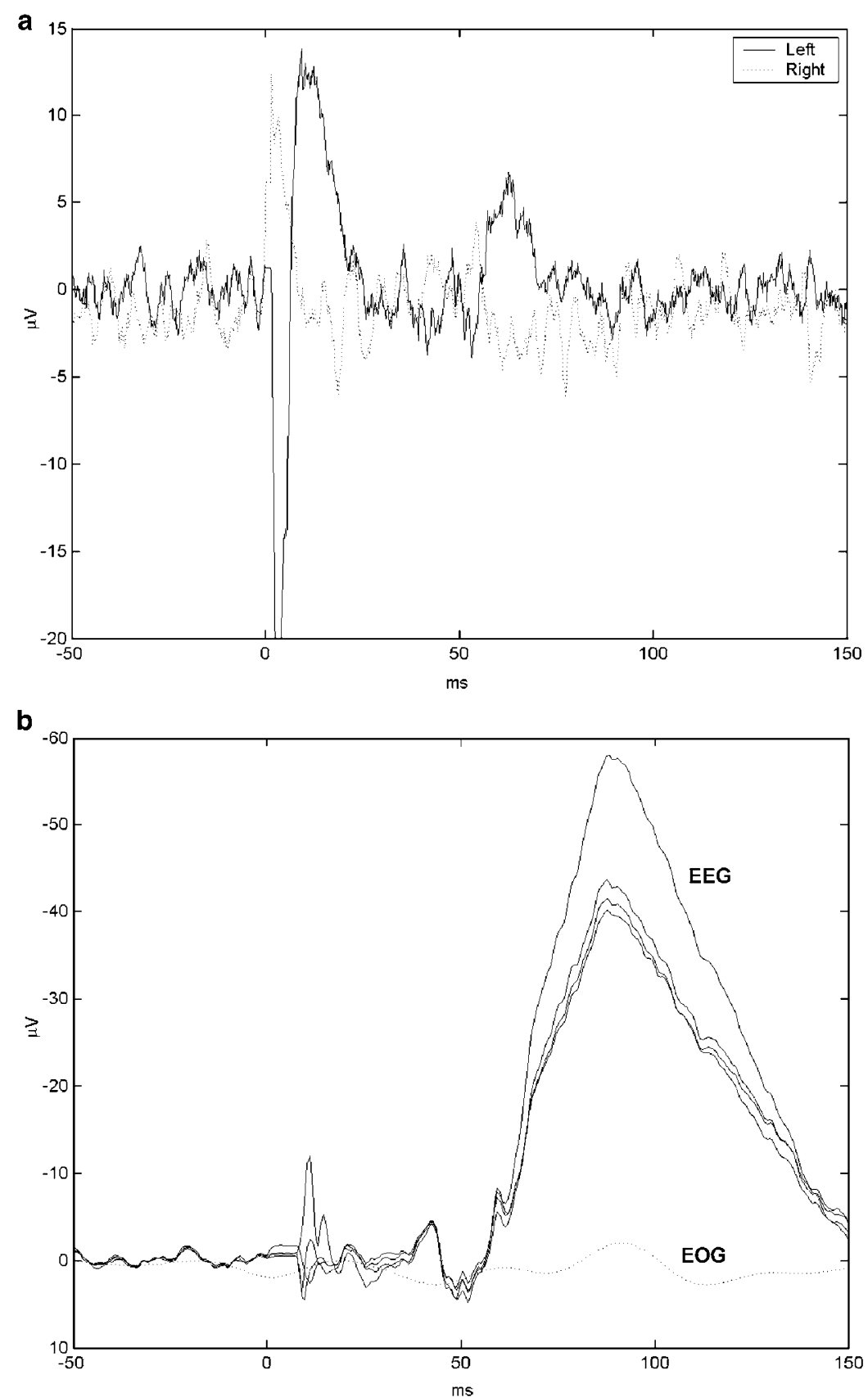

Figure 4 (a) Averaged EMG to the left prefrontal TMS pulses as recorded with the bipolar platinum electrodes in one subject from temporal muscles. (b) Horizontal electro-oculogram after prefrontal TMS in one subject (dotted line). EEG responses of the same subject from frontal electrodes (solid lines). Note that the EOG signal has been low-pass-filtered at $35 \mathrm{~Hz}$.

underlying the observed reduction of electrical activity by alcohol in the prefrontal cortex. Neurochemical effects other than GABA are also likely to exist, for example, the inhibition of $N$-methyl-D-aspartate-activated (NMDA) currents by ethanol (Lovinger et al, 1989). The NMDA antagonists memantine and riluzole have been shown to enhance intracortical inhibition and to reduce intracortical facilitation in comparison to placebo studied by TMS (Schwenkreis et al, 1999, 2000). Alcohol has also been shown to modulate dopamine function in the prefrontal cortex (Boone et al, 1997; Nielsen et al, 1999a, b). Recently, Strafella et al (2001) showed that $10-\mathrm{Hz}$ high-frequency
rTMS of the prefrontal cortex induces the release of endogenous dopamine from subcortical nuclei. Further, alcohol may change the function of serotonin (Yukhananov et al, 1992). Prefrontal TMS may modify the function of serotonin (Gur et al, 2000). Summarizing, the effects of alcohol after prefrontal TMS may be mediated through its interaction with GABA, NMDA/glutamate, dopamine, and/ or serotonin.

One confounding factor may be related to the test-retest study design (separated from each other by at least $1.5 \mathrm{~h}$ ) used by us. The suppression of motor cortex excitability after low-frequency rTMS has been shown to exert effects 
lasting beyond the time of stimulation (Wassermann et al, 1996; Chen et al, 1997), but was not supported by Siebner et al (1999). In the latter study motor cortex TMS did not change motor-evoked-potential input-output curves after $30 \mathrm{~min}$ of $1-\mathrm{Hz}$ stimulation. Furthermore, the excitability of the prefrontal cortex is lower than that of the motor cortex (Kähkönen et al, submitted). It is unlikely that in our study $0.4-0.7 \mathrm{~Hz}$ TMS with 120 stimuli (lasting for 4 min only) could decrease the excitability of the prefrontal cortex after $1.5 \mathrm{~h}$. However, the single-pulse technique used by us does not allow the separation of cortical inhibition and facilitation. In the future, placebo-controlled studies with a paired-pulse technique will allow one to take into consideration the possible confounding factors and expand our understanding on the effects of alcohol on different cortical processes.

The reduction of TMS-evoked electrical activity following alcohol ingestion is in line with the results of glucose metabolism studies in humans and animals. These studies have shown that alcohol decreases CMRglu in the cortex, in particular in the prefrontal areas. Whole-brain CMRglu, studied by positron emissiontomography, was decreased after the administration of alcohol, in particular at a dose of $0.8 \mathrm{~g} / \mathrm{kg}$ (the dose we used in this study). The decreased CMRglu was marked in frontal cortices bilaterally (De Wit et al, 1990). At a higher dose $(1 \mathrm{~g} / \mathrm{kg})$, alcohol decreased cortical (including prefrontal areas) and cerebellar CMRglu with relative sparing of the basal ganglia and corpus callosum (Volkow et al, 1990). The decrease of CMRglu after alcohol administration was also documented in in vivo autoradiographic studies in rats (Eckardt et al, 1988). In these studies, changes in brain functions after alcohol administration were detected with a time resolution of minutes. In contrast to this, TMS allowed us to excite the prefrontal cortex locally and to monitor changes of neuronal activity directly by high-resolution EEG in millisecond accuracy.

In conclusion, alcohol-reduced cortical excitability was detected by focal prefrontal magnetic stimulation combined with high-resolution EEG. The reduction of prefrontal excitability may be associated with symptoms of alcohol intoxication such as mood lability and impairments in attention, memory, and judgement.

\section{ACKNOWLEDGEMENTS}

This work was supported by Helsinki University Central Hospital Research Funds and the Academy of Finland. We thank Matti Holi, MD and Jari Karhu, MD, PhD for helping with the experiments, and also Jarmo Ruohonen, $\mathrm{PhD}$ for calculations of the induced field by the TMS coil.

\section{REFERENCES}

Barker AT (1991). An introduction to the basic principles of magnetic nerve stimulation. J Neurophysiol 8: 26-37.

Bohning DE, Shastri A, McConnel KA, Nahas Z, Lorberbaum JP, Roberts DR et al (1999). A combined TMS/fMRI study of intensity-dependent TMS over motor cortex. Biol Psychiatry 45: 385-394.
Boone EM, Cook MN, Hou X, Jones BC (1997). Sex and strain influence the effect of ethanol on central monoamines. J Stud Alcohol 58: 590-599.

Chen R, Classen J, Gerloff C, Celnik P, Wassermann EM, Hallett M et al (1997). Depression of motor cortex excitability by lowfrequency transcranial magnetic stimulation. Neurology 48: 1398-1403.

De Wit H, Metz J, Wagner N, Cooper M (1990). Behavioral and subjective effects of ethanol: relationship of cerebral metabolism using PET. Alcohol Clin Exp Res 14: 482-489.

Eckardt MJ, Cambell GA, Marietta ChA, Majchrowicz E, Weight F (1988). Acute ethanol administration selectively alters localized cerebral glucose metabolism. Brain Res 444: 53-58.

Ehlers CL, Wall TL, Schuckit MA (1989). EEG spectral characteristics following ethanol administration in young men. Electroencephalogr Clin Neurophysiol 73: 179-187.

Gur E, Lerer B, Dremencov E, Newman ME (2000). Chronic repetitive transcranial magnetic stimulation induces subsensitivity of presynaptic serotonergic autoreceptor activity in rat brain. Neuroreport 11: 2925-2929.

Hämäläinen MS, Ilmoniemi RJ (1994). Interpreting magnetic fields of the brain: minimum-norm estimates. Med Biol Eng Comput 32: $35-42$.

Ilmoniemi RJ, Virtanen J, Ruohonen J, Karhu J, Aronen H, Näätänen $\mathrm{R}$ et al (1997). Neuronal responses to magnetic stimulation reveal cortical reactivity and connectivity. NeuroReport 8: 3537-3540.

Kähkönen S, Holi M, Wilenius J, Karhu J, Nikouline VV, Bailey CJ et al (2001a). The functional connectivity of the prefrontal cortex studied by combined TMS with EEG. Biomed Tech 46: 257-259.

Kähkönen S, Kesäniemi M, Nikouline VV, Karhu J, Ollikainen M, Holi $\mathrm{M}$ et al (2001b). Ethanol modulates cortical activity: direct evidence with combined TMS and EEG. NeuroImage 14: 322328.

Kähkönen S, Komssi S, Wilenius J, Ilmoniemi RJ (2002). Reactivity of the prefrontal cortex as a function of TMS stimulus intensity. An EEG study. In: Nowak H, Kaueisen J, Giessler F, Huonker R (eds). Proceedings of the 13th International Conference on Biomagnetism. VDE Verlag: Berlin. pp 1082-1083.

Kähkönen S, Wilenius J, Ilmoniemi RJ. Distinct differences in cortical reactivity of motor and prefrontal cortices to magnetic stimulation: implications for depression. submitted.

Komssi S, Aronen HJ, Huttunen J, Kesäniemi M, Soinne L, Nikouline VV et al (2002). Ipsi- and contralateral EEG reactions to transcranial magnetic stimulation. Clin Neurophysiol 113: $175-184$.

Korpi ER (1994). Role of $\mathrm{GABA}_{\mathrm{A}}$ receptors in the actions of alcohol and in alcoholism: recent advances. Alcohol Alcohol 29: 115-129.

Lehmann D, Skrandies W (1980). Segmentation of EEG potential fields. Electroencephalogr Clin Neurophysiol 38: 27-32.

Lehtinen I, Nyrke J, Lang A, Pakkanen A, Keskinen E (1985). Individual alcohol reaction profiles. Alcohol 2: 511-513.

Lovinger DM, White G, Weight FF (1989). Ethanol inhibits NMDAactivated ion current in hippocampal neurons. Science 243: $1721-1724$.

Lukas SE, Mendelson JH, Benedict RA, Jones B (1986). EEG alpha activity increases during transient episodes of ethanol-induced euphoria. Pharmacol Biochem Behav 25: 889-895.

Marshall AW, Kingstone D, Boss M, Morgan MY (1983). Ethanol elimination in males and females: relationship to menstrual cycle and body composition. Hepatology 3: 701-706.

Matthew RI, Wilson WH (1986). Regional cerebral blood flow changes associated with ethanol intoxication. Stroke 17: 11561159.

Morita H, Baumagarten J, Petersen N, Christensen LOD, Nielsen J (1999). Recruitment of extensor-carpi-radialis motor units by 
transcranial magnetic stimulation and radial-nerve stimulation in human subjects. Exp Brain Res 128: 557-562.

Newlin DB, Golden CJ, Quqite M, Graber B (1982). Effects of alcohol ingestion on regional cerebral blood flow. Int J Neurosci 17: $145-150$.

Nielsen DM, Crosley KJ, Keller Jr RW, Glick SD, Carlson JN (1999a). Ethanol induced differences in medial prefrontal cortex dopamine asymmetry and in nucleus accumbens dopamine metabolism in left- and right-turning rats. Brain Res 823: 207-212.

Nielsen J, Morita H, Baumgarten J, Petersen N, Christensen LOD (1999b). On the comparability of H-reflexes and MEPs. In Paulus W, Hallett M, Rossini PM, Rothwell JC (eds). Proceedings of the International Symposium on Transcranial Magnetic Stimulation. Electroencephalogr Clin Neurophysiol 51(Suppl): 93-101.

Nikouline V, Ruohonen J, Ilmoniemi RJ (1999). The role of the coil click in TMS assessed with simultaneous EEG. Clin Neurophysiol 110: $1325-1328$.

Rosenthal J, Waller HJ, Amassian VE (1967). An analysis of the activation of motor cortical neurons by surface stimulation. $J$ Neurophysiol 30: 844-858.

Schwartz JA, Speed NM, Gross MD, Lucey MR, Bazakis AM, Hariharan M et al (1993). Acute effects of alcohol administration on regional cerebral blood flow: the role of acetate. Alcoholism Clin Exp Res 17: 1119-1123.

Schwarz E, Kielholz P, Hobi V, Golberg L, Gilsdorf U, Hofstetter M et al (1981). Alcohol-induced biphasic background and stimulus-elicited EEG changes in relation to blood levels. Int J Clin Pharmacol Ther Toxicol 19: 102-111.

Schwenkreis P, Liepert J, Witscher K, Fischer W, Weiller C, Malin JP et al (2000). Riluzole suppresses motor cortex facilitation in correlation to its plasma level. A study using transcranial magnetic stimulation. Exp Brain Res 135: 293-299.

Schwenkreis P, Witscher K, Janssen F, Addo A, Dertwinkel R, Zenz $\mathrm{M}$ et al (1999). Influence of the $N$-methyl-D-aspartate antagonist memantine on human motor cortex excitability. Neurosci Lett 270: $137-140$.
Siebner HR, Tormos JM, Ceballos-Baumann AO, Auer C, Catala MD, Conrad B et al (1999). Low-frequency repetitive transcranial magnetic stimulation of the motor cortex in writer's cramp. Neurology 52: 529-537.

Starck J, Rimpiläinen I, Pyykkö I, Toppila E (1996). The noise level in magnetic stimulation. Scand Audiol 4: 223-226.

Strafella AP, Paus T, Barrett J, Dagher A (2001). A repetitive transcranial magnetic stimulation of the human prefrontal cortex induces dopamine release in the caudate nucleus. $J$ Neurosci 21: 1-4.

Tiihonen J, Kuikka J, Hakola P, Paanila J, Airaksinen J, Eronen M et al (1994). Acute ethanol-induced changes in cerebral blood flow. Am J Psychiatry 151: 1505-1508.

Tiitinen H, Virtanen J, Ilmoniemi RJ, Kamppuri J, Ollikainen M, Ruohonen J et al (1999). Separation of contamination caused by coil clicks from responses elicited by transcranial magnetic stimulation. Clin Neurophysiol 110: 982-985.

Ziemann U, Lönnecker S, Paulus W (1995). Inhibition of human motor cortex by ethanol. A transcranial magnetic stimulation study. Brain 118: 1437-1446.

Virtanen J, Ruohonen J, Näätänen R, Ilmoniemi RJ (1999). Instrumentation for the measurement of electric brain responses to transcranial magnetic stimulation. Med Biol Eng Comp 37: 322-326.

Volkow N, Hitzemann AP, Wolf JL, Fowler JS, Christman D, Dewey $S$ et al (1990). Acute effects of ethanol on regional brain glucose metabolism and transport. Psychiatr Res 35: 39-48.

Volkow ND, Mullani N, Gould L, Adler SS, Guynn RW, Overall JE et al (1988). Effects of acute alcohol intoxication on cerebral blood flow measured with PET. Psychiatr Res 24: 201-209.

Wassermann EM, Grafman J, Berry C, Hollnagel C, Wild K, Clark $\mathrm{K}$ et al (1996). Use and safety a new repetitive trancranial magnetic stimulator. Electroencephalogr Clin Neurophysiol 101: 312-417.

Yukhananov RY, Tennilä TM, Miroshnicenko TI, Kudrin VS, Ushakov AN, Melnik EI et al (1992). Ethanol and delta-sleepinducing peptide: effects on brain monoamines. Pharmacol Biochem Behav 43: 683-687. 